\title{
TRAIL mediates apoptosis in cancerous but not normal primary cultured cells of the human reproductive tract
}

\author{
Anil Sadarangani - Sumie Kato • Natalia Espinoza • Soledad Lange • Carmen Llados • \\ Marisol Espinosa • Manuel Villalón · Stanley Lipkowitz • Mauricio Cuello • \\ Gareth I. Owen
}

Published online: 3 January 2007

C Springer Science + Business Media, LLC 2007

In the article by Anil Sadarangani et al., entitled "TRAIL mediates apoptosis in cancerous but not normal primary cultured cells of the human reproductive tract" some of the grant information appeared incorrectly.

The correct grant information is as follows:

This work was supported by a grant from the Wellcome Trust GR071469 (GIO) and the Chilean national science grants FONDECYT 1060495 (GIO) and 1050744 (MC).

The online version of the original article can be found at http://dx.doi.org/10.1007/s10495-006-0492-z

A. Sadarangani $\cdot$ N. Espinoza $\cdot$ S. Lange $\cdot$ C. Llados .

M. Espinosa · M. Villalón · G. I. Owen ( $\square)$

Department of Physiology, Faculty of Biological Sciences,

Pontificia Universidad Católica de Chile,

Alameda 340, Santiago, Chile

e-mail: gowen@bio.puc.cl

S. Kato $\cdot$ M. Cuello

Departament of Obstetrics and Gynecology, Faculty of Medicine, Pontificia Universidad Católica de Chile,

Alameda 340, Santiago, Chile

S. Lipkowitz

Laboratory of Cellular and Molecular Biology, Center for Cancer

Research, NCI,

Bethesda, MD 20892, USA 